\section{OAK RIDGE}

NATIONAL

LABORATORY

UT-Battelle
A Method for Concurrent and Continuous Measurement of Rn-222 and Rn-220 Using Scintillation Cells

\author{
R. L. Coleman
}

Life Sciences Division 


\title{
A Method for Concurrent and Continuous Measurement of Rn-222 and Rn-220 Using Scintillation Cells
}

\author{
Robert L. Coleman \\ Life Sciences Division
}

February 2002

\author{
Prepared by \\ OAK RIDGE NATIONAL LABORATORY \\ P.O. Box 2008 \\ Oak Ridge, Tennessee 37831-6285 \\ managed by \\ UT-Battelle, LLC \\ for the \\ U.S. DEPARTMENT OF ENERGY \\ under contract DE-AC05-00OR22725
}




\section{DOCUMENT AVAILABILITY \\ [DOES NOT APPLY TO DRAFT DOCUMENTS]}

Reports produced after January 1, 1996, are generally available free via the U.S. Department of Energy (DOE) Information Bridge:

Web site: http://www.osti.gov/bridge

Reports produced before January 1, 1996, may be purchased by members of the public from the following source:

National Technical Information Service

5285 Port Royal Road

Springfield, VA 22161

Telephone: 703-605-6000 (1-800-553-6847)

TDD: 703-487-4639

Fax: 703-605-6900

E-mail: info@ntis.fedworld.gov

Web site: http://www.ntis.gov/support/ordernowabout.htm

Reports are available to DOE employees, DOE contractors, Energy Technology Data Exchange (ETDE) representatives, and International Nuclear Information System (INIS) representatives from the following source:

Office of Scientific and Technical Information

P.O. Box 62

Oak Ridge, TN 37831

Telephone: 865-576-8401

Fax: 865-576-5728

E-mail: reports@adonis.osti.gov

Web site: http://www.osti.gov/contact.html

This report was prepared as an account of work sponsored by an agency of the United States Government. Neither the United States government nor any agency thereof, nor any of their employees, makes any warranty, express or implied, or assumes any legal liability or responsibility for the accuracy, completeness, or usefulness of any information, apparatus, product, or process disclosed, or represents that its use would not infringe privately owned rights. Reference herein to any specific commercial product, process, or service by trade name, trademark, manufacturer, or otherwise, does not necessarily constitute or imply its endorsement, recommendation, or favoring by the United States Government or any agency thereof. The views and opinions of authors expressed herein do not necessarily state or reflect those of the United States Government or any agency thereof. 


\section{CONTENTS}

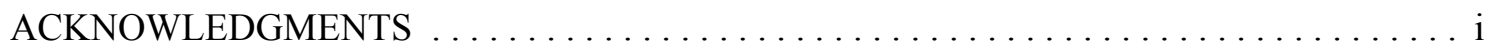

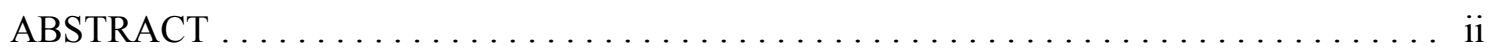

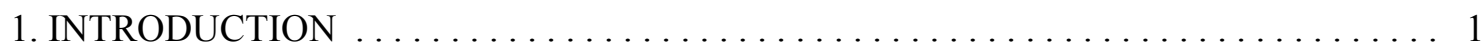

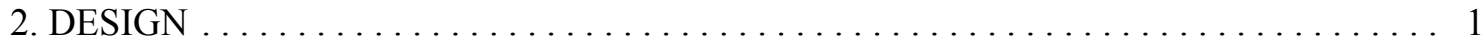

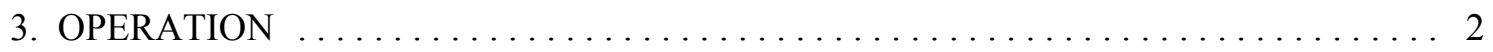

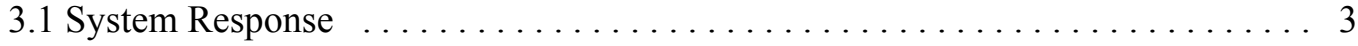

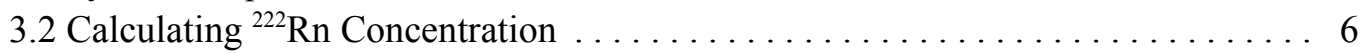

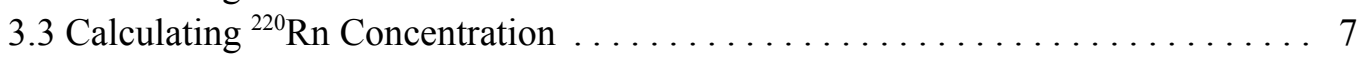

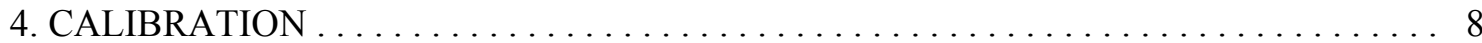

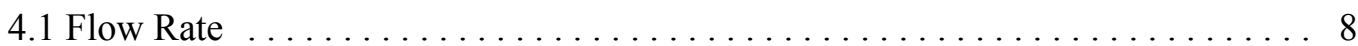

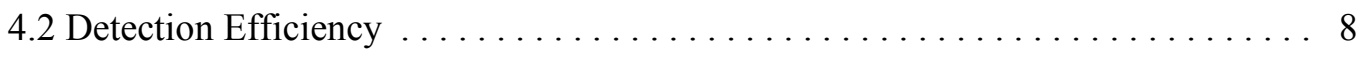

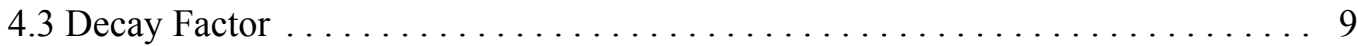

5. LABORATORY TEST \& FIELD APPLICATION $\ldots \ldots \ldots \ldots \ldots \ldots \ldots \ldots$

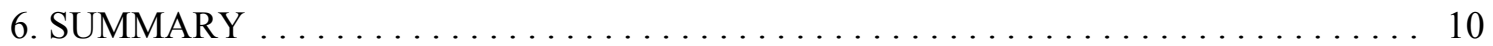

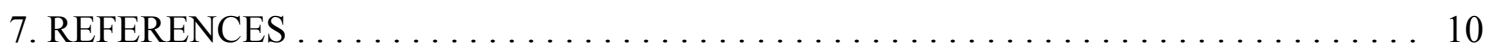




\section{ACKNOWLEDGMENTS}

This project was sponsored by the U.S. Department of Energy's Office of Environmental Management during the time period of 1997 to 1998 as part of the Molten Salt Reactor Experiment Decommissioning project at Oak Ridge National Laboratory. The author wishes to acknowledge the support, assistance, and interest of R. L. Faulkner, F. J. Peretz, J. M. Rushton, and R. M. Szozda of the Molten Salt Reactor Remediation Project, where this method was originally applied. The author also acknowledges valuable technical assistance from M. E. Murray and editorial assistance from M. S. Uziel, both of the Measurement Applications and Development Group. 


\begin{abstract}
A method is described for the continuous and simultaneous measurement of both ${ }^{220} \mathrm{Rn}$ and ${ }^{222} \mathrm{Rn}$ in air. Two scintillation flasks are arranged in a serial configuration and the concentrations of ${ }^{222} \mathrm{Rn}$ and ${ }^{220} \mathrm{Rn}$ are determined by making use of the difference between the half-lives of the two radon isotopes. The method was developed for directly measuring ${ }^{220} \mathrm{Rn}$ in occupied areas where fuel materials containing ${ }^{228} \mathrm{Th}$ were being used, but could also be useful for other applications. Since ${ }^{222} \mathrm{Rn}$ is usually present from either naturally occurring materials or due to the presence of process material, the method was designed to allow measurement of the two isotopes at coincident times. The method is discussed for counting equipment using scintillation cells, but the approach would also be directly applicable for any type of pulse-counting radon monitoring equipment such as pulse-ion chambers. Although intermittent measurements with decay correction could be performed using a single detector, the use of two cells allows continuous monitoring and a higher degree of detection sensitivity. The approach makes use of isotope-independent calibration factors and could therefore easily be modified for use with a single detector when only one of the radon isotopes is expected to be present.
\end{abstract}




\section{INTRODUCTION}

The half-life of ${ }^{222} \mathrm{Rn}$ is 3.8 days while the half-life of ${ }^{220} \mathrm{Rn}$ is only about 55 seconds. This fundamental difference of property allows the convenient separation of one radon isotope from the other by measuring the concentration in an air volume at two separate times. This concept has been incorporated into a continuous monitor by placing two scintillation cell detectors in a serial configuration with a delay line between the two. Ambient air is passed through a fibrous filter and brought into the first detector with virtually no delay (e.g., the travel time into the cell is minimal). The air circulates through the first cell and then continues through a delay volume to a second, identical detection cell. The net output from each of the cells is unfolded using a simple mathematical relationship that accounts for the decay between the two cells to give the concentrations of ${ }^{222} \mathrm{Rn}$ and ${ }^{220} \mathrm{Rn}$ in the air entering the system.

The method was developed to meet measurement requirements during decommissioning operations at the previous Molten Salt Reactor Experiment located at Oak Ridge National Laboratory. The fuel used in the reactor was ${ }^{233} U$ and contained ${ }^{232} U$ as a contaminant. The ${ }^{232} \mathrm{U}$ produces ${ }^{220} \mathrm{Rn}$ which can easily escape into the ambient air occupied by workers. Since ${ }^{222} \mathrm{Rn}$ is also present in the area due to natural materials, it was important to resolve the concentration of each isotope so that the source of any elevated measurements could be well understood even at low concentrations. Scintillation cells were chosen because of the high intrinsic efficiency associated with this type of detector, thereby allowing measurements at low concentrations with good statistical certainty. Additionally, the system was designed using off-the-shelf components to allow relatively easy construction and maintenance.

\section{DESIGN}

Figure 1 shows a schematic of the detection system. The detectors used are scintillation flasks, which are commonly known as Lucas cells — named after the man who first developed the technique (Lucas 1957). The cells, or flasks, are equipped with input and output orifices such that air can be drawn through the sensitive volumes. The cells are coated on the inside with a $\mathrm{ZnS}(\mathrm{Ag})$ scintillant that allows the indirect detection of energetic particles impinging the wall by detecting the light emitted with photo-detectors coupled to the cell. The detection system is calibrated so that only large pulses, such as those from alpha interactions within the scintillant, are detected. The result for this configuration is that alpha emitting radionuclides in the air passing through the cells are detected with a relatively high efficiency. At the input, the air is drawn through a fibrous filter that removes charged molecules and aerosols, thereby allowing only gases that do not react with the filter to enter the chamber. Note also, that although scintillation cells are being discussed in this report, that the method is directly applicable to any type of pulsecounting radon measurement equipment such as pulse-ion chambers.

A data logger is used for recording the output from each of the cells and can then be used to download the information into a personal computer at a later time. A calculation 


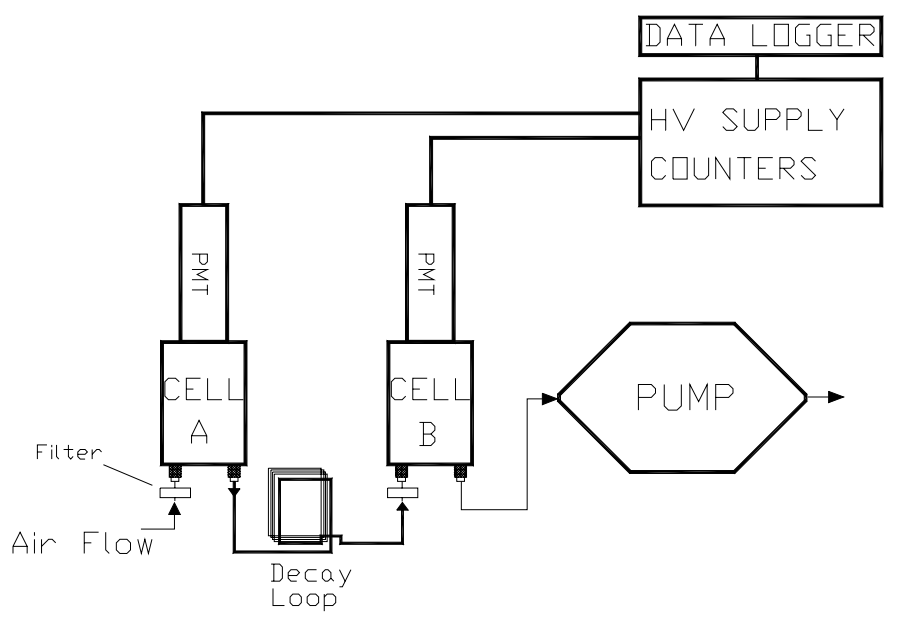

Figure 1 Schematic showing general design components for the radon detection system.

is performed for each time interval to determine the radon concentration for each of the isotopes during that interval.

\section{OPERATION}

The output from each of the two detectors can be described in its simplest form as two linear equations in two unknowns.

$$
\begin{aligned}
& C_{1}=\left(R \alpha_{R}+T \alpha_{T}\right) E_{1}+B_{1} \\
& C_{1}=\left(R \alpha_{R}+\Lambda T \alpha_{T}\right) E_{2}+B_{2}
\end{aligned}
$$

where,

$\mathrm{C}_{1}, \mathrm{C}_{2}=$ observed counts for the first and the second cell, respectively during a measurement period.

$\mathrm{R}, \mathrm{T}=$ number of disintegrations of ${ }^{222} \mathrm{Rn}(R)$ and ${ }^{220} \mathrm{Rn}(T)$ that occurred during the measurement period in the first cell. These variables represent direct decays of the radon parent atoms.

$\alpha_{\mathrm{R}}, \alpha_{\mathrm{T}}=$ number of alpha emissions per decay of ${ }^{222} \mathrm{Rn}$ and ${ }^{220} \mathrm{Rn}$, respectively, including those emitted by progeny that have deposited within the chamber.

$\mathrm{E}_{1}, \mathrm{E}_{2}=$ detection efficiency for the first and second cell (counts per alpha decay). As used in these general equations, the detection efficiencies are average efficiencies and represent the combined detection ability for the gaseous radon and the progeny attached to the walls of the cells. 
$\Lambda \quad=$ decay factor for ${ }^{220} \mathrm{Rn}$ while passing from the first to the second cell. (This is an experimentally determined value and is unique for a given system and flow rate.)

$\mathrm{B}_{1}, \mathrm{~B}_{2}=$ Background counts expected for each cell during the measurement period.

\subsection{System Response}

Equation 1 provides a simple description of the system but is only accurate when generalized assumptions are applied. For example, it must be assumed that the detection efficiency for the radon gas and the daughter products plated to the inside of a cell are the same and also that all progeny produced inside a cell remain there. Another limitation is that a 3 to 4 hour sampling period is needed for ${ }^{222} \mathrm{Rn}$ so that the progeny activities have time to equilibrate with the parent. A more exact description of the system can be derived when an iterative measurement method is used. Since such a system is designed to collect data on a periodic interval, a solution can be formulated which tracks the independent contributions from each of the isotopes being measured. The following equation set describes the output from the cells in a more exact manner and references all sources of counts as separate parameters by allowing use of the results from previous measurements.

$$
C_{1}=(R+2 T) \mathcal{E}_{G 1}+f \mathcal{E}_{P 1}\left(k_{A} R+k_{C} R+k_{D} T+P_{R}+P_{T}\right)+B_{1},
$$

and

$$
C_{2}=(R+2 \Lambda T) \varepsilon_{G 2}+f \mathcal{E}_{P 2}\left(k_{A} R+k_{C} R+\Lambda k_{D} T+P_{R}+\Lambda P_{T}\right)+B_{2},
$$

where,

$$
\begin{aligned}
\varepsilon_{\mathrm{G} 1}, \varepsilon_{\mathrm{G} 2}= & \text { detection efficiency for decays occurring in the gas }(\mathrm{G}) \text { for the first and } \\
& \text { second cell, respectively. } \\
\varepsilon_{\mathrm{P} 1}, \varepsilon_{\mathrm{P} 2}= & \text { detection efficiency for decays occurring from progeny atoms that have } \\
& \text { plated to the walls of the cells for the first and second cell, respectively. } \\
& \text { This includes all progeny of the two radon isotopes with the exception } \\
& \text { of the first }{ }^{220} \mathrm{Rn} \text { daughter, }{ }^{216} \mathrm{Po} \text {, which is assumed to primarily } \\
& \text { undergo decay while still in the gas since its half life is only } 0.15 \\
& \text { seconds. } \\
= & \text { plate-out fraction for the progeny. This factor represents the fraction } \\
& \text { of daughter atoms produced in a cell that will plate to the inside walls. } \\
& \text { The factor will be equivalent for two identical cells at a given flow } \\
& \text { rate. } \\
= & \text { constants predicting the number of decays for each daughter during the } \\
& \text { count interval as a function of the number of radon parent decays that } \\
& \text { occurred. The factors are pre-determined constants for a given time } \\
& \text { interval and only account for atoms produced directly by radon decays } \\
& \text { during the interval }- \text { e.g., decays of progeny present in the cells from } \\
& \text { previous intervals are not included. The factors represent decays of the } \\
& \text { following daughters: } k_{A}={ }^{218} \text { Po (Ra-A), } k_{C}={ }^{214} \text { Po (Ra-CN and } k_{D}=
\end{aligned}
$$


${ }^{212} \mathrm{Bi}$ (Th-C). Note that there is the equivalent of one alpha decay for each decay of these daughters. Valid values for $k_{A}, k_{C}$, and $k_{D}$ are given in Table 1 and are further described in a later section.

$\mathrm{P}_{\mathrm{R}}, \mathrm{P}_{\mathrm{T}} \quad=$ number of alpha decays during the count interval from long lived progeny that were present in the first cell prior to the start of the interval.

The number of alpha decays, $P_{R}$ and $P_{T}$, that occur during the count interval as a result of radon progeny produced prior to the measurement period can be calculated as

$$
P_{R}=\int_{0}^{t} R_{A_{i}} e^{-\lambda_{A} t}+\int_{0}^{t} R_{C_{i}} e^{-\lambda_{C} t}=\frac{R_{A_{i}}\left(1-e^{-\lambda_{A} t}\right)}{\lambda_{A}}+\frac{R_{C_{i}}\left(1-e^{-\lambda_{C} t}\right)}{\lambda_{C}},
$$

and

$$
P_{T}=\int_{0}^{t} T_{D_{i}} e^{-\lambda_{D} t}=\frac{T_{D_{i}}\left(1-e^{-\lambda_{D} t}\right)}{\lambda_{D}} .
$$

Where,

$\mathrm{R}_{\mathrm{A}}, \mathrm{R}_{\mathrm{C}}, \mathrm{T}_{\mathrm{Di}}=$ activity at the start of the interval, in disintegrations per minute (dpm), for each of the radon progeny of interest in the first cell. These parameters correlate to the isotopes ${ }^{218} \mathrm{Po}\left(\mathrm{R}_{\mathrm{A}}\right),{ }^{214} \mathrm{Bi}\left(\mathrm{R}_{\mathrm{C}}\right)$ and ${ }^{212} \mathrm{Bi}\left(\mathrm{T}_{\mathrm{D}}\right)$, respectively. The activities are calculated for the start of each interval by use of information from prior intervals as

$$
\begin{gathered}
R_{A_{i}}=R_{A_{i-1}} e^{-\lambda_{A} t}+j_{A} \frac{R_{i-1}}{t}, \\
R_{B_{i}}=R_{B_{i-1}} e^{-\lambda_{B} t}+j_{B_{1}} \frac{R_{i-1}}{t}+j_{B_{2}} R_{A_{i-1}}, \\
R_{C_{i}}=R_{C_{i-1}} e^{-\lambda_{C} t}+j_{C_{1}} \frac{R_{i-1}}{t}+j_{C_{2}} R_{A_{i-1}}+j_{C_{3}} R_{B_{i-1}}, \\
T_{B_{i}}=T_{B_{i-1}} e^{-\lambda_{T_{B}} t}+j_{T_{B}} \frac{T_{i-1}}{t},
\end{gathered}
$$

and

$$
T_{D_{i}}=T_{D_{i-1}} e^{-\lambda_{D} t}+j_{D_{1}} \frac{T_{i-1}}{t}+j_{D_{2}} T_{B_{i-1}}
$$

Note that these values are calculated as if all of the progeny plate to the inside of the cells - e.g. as if $f=1$. The plate out fraction, $f$, is accounted for separately in Equations 2 and 3. 
$\lambda_{\mathrm{x}}=\quad$ decay constant for each daughter of interest $\left(\mathrm{min}^{-1}\right)$.

$$
\begin{array}{ll}
{ }^{218} \mathrm{Po}\left(\lambda_{\mathrm{A}}\right) & =2.3 \mathrm{e}-01 \mathrm{~min}^{-1} \\
{ }^{214} \mathrm{~Pb}\left(\lambda_{\mathrm{B}}\right) & =2.6 \mathrm{e}-02 \mathrm{~min}^{-1} \\
{ }^{214} \mathrm{Bi}\left(\lambda_{\mathrm{C}}\right) & =3.5 \mathrm{e}-02 \mathrm{~min}^{-1} \\
{ }^{212} \mathrm{~Pb}\left(\lambda_{\mathrm{T}_{\mathrm{B}}}\right) & =1.1 \mathrm{e}-03 \mathrm{~min}^{-1} \\
{ }^{212} \mathrm{Bi}\left(\lambda_{\mathrm{D}}\right) & =1.1 \mathrm{e}-02 \mathrm{~min}^{-1}
\end{array}
$$

$\mathrm{t}=$ length of the count interval being used ( $\mathrm{min})$

$\mathrm{R}_{\mathrm{i}-1,} \mathrm{~T}_{\mathrm{i}-1}=$ decays of each radon isotope, ${ }^{222} \mathrm{Rn}(\mathrm{R})$ or ${ }^{220} \mathrm{Rn}(\mathrm{T})$, observed during the previous measurement interval.

$\mathrm{j}_{\mathrm{A}}, \mathrm{j}_{\mathrm{C}}, \mathrm{j}_{\mathrm{D}}=$ constant for the time interval, $t$, that predicts the daughter equilibrium activity that would accrue due to radon decays during the period. Each constant is pre-determined as a function of the interval length chosen and is expressed as a ratio of the daughter activity to the measured radon or thoron activity, $\mathrm{R} / \mathrm{t}$ and $\mathrm{T} / \mathrm{t}$. The constants therefore have a unity dimension. Values for $j_{A}, j_{C}$, and $j_{D}$ as a function of the length of time interval used are given in Table 1.

Equations 2 and 3 can be rearranged and solved as a system of two linear equations in two unknowns. Introducing substitutions as

$$
\begin{gathered}
Z_{1}=\mathcal{E}_{G 1}+Y_{1}\left(k_{A}+k_{C}\right), \\
Z_{2}=\varepsilon_{G 2}+Y_{2}\left(k_{A}+k_{C}\right), \\
Y_{1}=f \mathcal{E}_{P 1},
\end{gathered}
$$

and

$$
Y_{2}=f \mathcal{E}_{P 2}
$$

a solution for the number of decays during a count interval, due solely to ${ }^{220} \mathrm{Rn}$ in the first cell, can be calculated as

$$
T=\frac{Z_{2}\left(C_{1}-Y_{1}\left(P_{R}+P_{T}\right)-B_{1}\right)-Z_{1}\left(C_{2}-Y_{2}\left(P_{R}+\Lambda P_{T}\right)-B_{2}\right)}{Z_{2}\left(2 \varepsilon_{G 1}+Y_{1} k_{D}\right)-Z_{1} \Lambda\left(2 \varepsilon_{G 2}+Y_{2} k_{D}\right)} .
$$

Once the result for $T$ has been determined, the value can be directly substituted into Equation 2 to solve for the number of decays during the count interval due solely to ${ }^{222} \mathrm{Rn}$, $R$. A valid solution is

$$
R=\frac{C_{1}-T\left(2 \mathcal{E}_{G 1}+Y_{1} k_{D}\right)-Y_{1}\left(P_{R}+P_{T}\right)-B_{1}}{Z_{1}} .
$$


The constants $\mathrm{k}_{\mathrm{A}}, \mathrm{k}_{\mathrm{C}}, \mathrm{k}_{\mathrm{D}}, \mathrm{j}_{\mathrm{A}}, \mathrm{j}_{\mathrm{C}}$, and $\mathrm{j}_{\mathrm{D}}$ are pre-determined based on known empirical relationships between the radon isotopes and their progeny. The $k$ coefficients give the number of decays that are expected for each of the alpha emitting progeny, neglecting plate-out percentage, as a direct function of the total number of radon decays during the interval. The $k$ coefficients only predict decays of daughter atoms generated as a direct result of radon transformations during the interval being evaluated and do not account for progeny created during previous intervals. A list of valid $k$ values is listed in Table 1 for each alpha emitting daughter as a function of the time interval used when collecting measurements. As an example of how these coefficients apply, consider a 30 minute count interval and assume that the number of ${ }^{222} \mathrm{Rn}$ decays during that time interval was 20 and the number of ${ }^{220} \mathrm{Rn}$ decays was also equal to 20 . Referencing Table 1, appropriate values of $\mathrm{k}_{\mathrm{C}}$ and $\mathrm{k}_{\mathrm{D}}$ for a 30 minute interval are 0.063 and 0.00019 , respectively. The number of ${ }^{214} \mathrm{Bi}(\mathrm{Ra}-\mathrm{C})$ decays that would be expected to occur as a result of ${ }^{222} \mathrm{Rn}$ decays during the same interval would be $20 \times 0.06$, which would result in about 1 alpha emission. Similarly, the number of ${ }^{212} \mathrm{Bi}(\mathrm{Th}-\mathrm{C})$ atoms that would be expected to decay as a result of the twenty ${ }^{220} \mathrm{Rn}$ transformations would be $20 \times 0.002$; resulting in less than one alpha emission after summing both the ${ }^{212} \mathrm{Bi}$ and subsequent ${ }^{212} \mathrm{Po}$ transformations.

The $j$ coefficients are pre-determined constants for estimating decays due to progeny plated to the inside of cells from previous intervals. The coefficients give the equilibrium activity for each daughter of interest that will accrue during a count interval, neglecting plate out percentage, and are a direct function of the parent radon activities during the period. A listing of coefficients is given in Table 1 as a function of the selected time interval used when collecting measurements. This parameter is used in Equations 6,7 and 8 to determine the activity of each daughter in the first cell at the start of an interval. These activities, in turn, are used in Equations 4 and 5 to determine the number of decays expected from each daughter during the period. As an example, suppose that an interval length of 30 minutes was being used and that the measured ${ }^{222} \mathrm{Rn}$ decays, $\mathrm{R}$, during an interval was determined to be 30 . This would equate to $\mathrm{a}^{222} \mathrm{Rn}$ decay rate, $\mathrm{P}_{\mathrm{R}}$, of 30 decays in $30 \mathrm{~min}$, or $1 \mathrm{dpm}$. Equation 3 would then used to estimate the activity of ${ }^{218} \mathrm{Po}(\mathrm{Ra}-\mathrm{A})$ for the start of the next period by use of a $j_{A}$ coefficient of 1.0. Assuming that no progeny existed prior to the start of the period, the equilibrium activity of ${ }^{218}$ Po that would have existed at the end of the interval would therefore have been approximately $1 \mathrm{dpm}$.

\subsection{Calculating ${ }^{222} \mathrm{Rn}$ Concentration}

Following the collection of data, the output from the system must be analyzed to determine the concentrations of ${ }^{222} \mathrm{Rn}$ and ${ }^{220} \mathrm{Rn}$ in the sampled air. This can be performed by either the collection system or by post-processing the accumulated count data at a later time.

The decay rate of ${ }^{222} \mathrm{Rn}$ in the cells is assumed to be equal to the activity in the air volume being sampled. This assumption can be made since the half-life of the ${ }^{222} \mathrm{Rn}$ is very long compared to the transit time through the measurement cells. The concentration of

${ }^{222} \mathrm{Rn}$ in the sampled air is calculated by accounting for the cell volume and count time as 


$$
R_{A}=\frac{R}{V t} \text {. }
$$

$R_{\mathrm{A}}$ represents the concentration of ${ }^{222} \mathrm{Rn}$ in the sampled air $(\mathrm{dpm} / \mathrm{L}), V$ is the volume of the scintillation cell (L) while $t$, as in other equations, is the length of the sample count interval (min).

The number of decays of ${ }^{222} \mathrm{Rn}, R$, is calculated from the net result of counts after contributions from progeny decays have been subtracted. An estimate of measurement error for ${ }^{222} \mathrm{Rn}$ results can be determined with less variability if the count contributions from the progeny decays are used. The total counts observed as a result of ${ }^{222} \mathrm{Rn}$ and subsequent progeny decays during the measurement interval will be

$$
C_{R}=R\left(\varepsilon_{G 1}+f \varepsilon_{P 1}\left(k_{A}+k_{C}\right)\right) \text {. }
$$

$\mathrm{C}_{\mathrm{R}}$ represents the total counts created by ${ }^{222} \mathrm{Rn}$ that entered the system during the measurement interval and can be used to estimate counting statisitics., i.e., measurement error. Note that count contributions from progeny created during prior time intervals are not included in $\mathrm{C}_{\mathrm{R}}$. For long count intervals during conditions where the radon concentration is not changing much, say on the order of 3 to 4 hours, the progeny will be in near secular equilibrium with the radon and $C_{R}$ will account for almost all decays of ${ }^{222} \mathrm{Rn}$ and its progeny.

\subsection{Calculating ${ }^{220} \mathrm{Rn}$ Concentration}

The half-life of ${ }^{220} \mathrm{Rn}$ is sufficiently short so that, except at a very high flow rate, an appreciable amount of decay is expected to occur during transit through a cell. The observed counts from ${ }^{220} \mathrm{Rn}$ decays, $\mathrm{T}$, over the measurement interval, $\mathrm{t}$, is actually the average decay rate in the first cell and does not necessarily represent the activity in the air volume being sampled. To calculate the ${ }^{220} \mathrm{Rn}$ concentration in the air volume at the point of input, a correction must be made for decay occurring before and during transit through the first cell. The observed ${ }^{220} \mathrm{Rn}$ decays, $\mathrm{T}$, can be represented mathematically as

$$
T=\frac{t}{\tau} \int_{0}^{\tau} T_{A} V e^{-\lambda t} d t
$$

In this equation $\tau$ represents the average transit time, in minutes, for atoms between the input and the output of the first cell (cell A in Fig. 1), $T_{A}$ is the concentration of ${ }^{220} \mathrm{Rn}$ in the air entering the first cell $(\mathrm{dpm} / \mathrm{L}), V$ is the volume of the cell $(\mathrm{L})$ and $\lambda$ is the decay constant for ${ }^{220} \mathrm{Rn}(0.76 / \mathrm{min})$. Solving and rearranging gives the concentration of ${ }^{220} \mathrm{Rn}$ in the input air, $T_{A}$, as:

$$
T_{A}=\frac{T \lambda \tau}{V t\left(1-e^{-\lambda \tau}\right)} .
$$


Assuming that a relatively uniform mixing condition occurs within a cell, the mean transit time, $\tau$, can be estimated by dividing the cell volume, $V(\mathrm{~L})$, by the volumetric flow rate of the air, $v(\mathrm{~L} / \mathrm{min})$, as

$$
\tau=\frac{V}{v}
$$

The mean transit time, $\tau$, can also be measured during calibration. A measurement would be collected in $\mathrm{a}^{220} \mathrm{Rn}$ atmosphere with and without a cell at the input to the system. The difference between the two measurements would be due solely to the decay of ${ }^{220} \mathrm{Rn}$ within the added cell. Given this, together with the known 55-s half-life of ${ }^{220} \mathrm{Rn}$, the mean transit time through the cell can be calculated.

Due to the stochastic nature of radioactive decay, the output from the system will often show negative results for one of the isotopes. Since this is not physically possible, an imposed logic can be used to correct the results. The logic is simple: if the result for one of the nuclides is negative, then assume that all of the activity is due to the presence of the other radon isotope. The result for this nuclide is then calculated while assuming that the other is not present. Following this method results in better statistics when only one of the radon isotopes is present at a detectable concentration.

\section{CALIBRATION}

Calibration methods are not discussed in detail since it is beyond the scope of this paper, however a brief summary of the parameters that must be determined is included for reference.

\subsection{Flow Rate}

The exact flow rate of the pump is not important, but the flow must remain relatively constant from the time of calibration since the decay coefficient, $\Lambda$, will be dependant on the rate of air movement between the first and second cell. When first testing the described method, a flow rate of $-0.5 \mathrm{~L} / \mathrm{m}$ was chosen such that the plate-out fraction would be high. Using this rate with $-300 \mathrm{~mL}$ cells, the plate-out coefficient was determined to be unity (e.g., the equilibrated activity of long-lived progeny was found to be equal to the activity of the radon in the cell).

\subsection{Detection Efficiency}

The detection efficiency for scintillation cells can be determined by using a flowthrough ${ }^{222} \mathrm{Rn}$ source, a standard calibration chamber or by injecting a well characterized ${ }^{222} \mathrm{Rn}$ sample into the unit and counting. The efficiency for decays in the gas as well as decays from daughters plated to the walls of the cells should be considered independently. If the two efficiencies are similar, then solutions to Equations 2 and 3 can be simplified. Similarly, if the two cells being used demonstrate very similar detection efficiencies then the equations can be reduced even further. 


\subsection{Decay Factor}

The decay factor can be measured by sampling an atmosphere of ${ }^{220} \mathrm{Rn}$ with the unit configured as depicted in Fig. 1. The exact concentration is not important since only the relative response between the two cells is needed for the flow rate selected. The decay factor, $\Lambda$, is calculated as:

$$
\Lambda \cdot \frac{C_{1}}{C_{2}}
$$

\subsection{Plate-out Factor}

The plate-out factor, $f$, is the fraction of daughter products that plate to the cell wall and will be a fixed value for a given cell design and flow rate. For low flow rates, say on the order of a liter per minute, this factor will typically be at or near unity - meaning that all progeny created inside of the cell remain there. This factor can be determined by exposing a cell for a period of four or more hours to ${ }^{222} \mathrm{Rn}$ at a flow rate of interest and then, following a complete purge with radon-free gas, comparing the rate of decreasing counts to that which would be expected if all progeny had indeed remained.

\section{LABORATORY TEST \& FIELD APPLICATION}

A unit was assembled to determine the ability for separating each of the radon isotopes and has since been used successfully for field measurements. A brief description of initial tests is now discussed to give an applied perspective of the method. A flow-through cylinder containing ${ }^{232} \mathrm{Th}$ was connected in series to the input of the test system for use as a source for ${ }^{220} \mathrm{Rn}$. The flow rate was set at $0.3 \mathrm{~L} / \mathrm{min}$ and data were collected at 1 -min intervals. A graphical representation of the measurements is given in Fig. 2. Note that the raw count data have been converted to $\mathrm{pCi} / \mathrm{L}$ alpha by accounting for the detection efficiency of each detector. The results give the total activity observed in each of the cells and are useful for determining the decay factor, $\Lambda$, as used in Eq. (1).

The unit was then tested under conditions where both ${ }^{222} \mathrm{Rn}$ and ${ }^{220} \mathrm{Rn}$ were simultaneously present at elevated levels. A flow-through cylinder containing ${ }^{226} \mathrm{Ra}$ was used as the source for ${ }^{222} \mathrm{Rn}$ in conjunction with the ${ }^{232} \mathrm{Th}$ source described above. During the test, a relatively low concentration of ${ }^{220} \mathrm{Rn}$ was used by diluting the output from the flow-through source into a larger volume. This was purposely done so that the separation ability for the two radon isotopes could be tested under conditions where the ratio between the concentration of ${ }^{222} \mathrm{Rn}$ to ${ }^{220} \mathrm{Rn}$ was high. The ${ }^{220} \mathrm{Rn}$ was turned on and measured alone

for a few minutes prior to turning on flow through the ${ }^{222} \mathrm{Rn}$ source. The ${ }^{222} \mathrm{Rn}$ concentration was allowed to gradually decrease for approximately 12 hours while still collecting data. The ${ }^{220} \mathrm{Rn}$ was then shut off and data were collected while only ${ }^{222} \mathrm{Rn}$ was being input to the system. Finally, all radon input flow was stopped and the system was purged with fresh air. Continued collection of the system output was performed while the longer-lived ${ }^{222} \mathrm{Rn}$ progeny decayed away inside the detectors. The direct, uncorrected measurement data are depicted in Fig. 3. 
The experimental unit was packaged and placed in a building where ${ }^{233} \mathrm{U}$ material had been used as part of a past operation at Oak Ridge National Laboratory (ORNL). ${ }^{232} \mathrm{U}$ is a contaminant in this material and, as a result, ${ }^{220} \mathrm{Rn}$ is an eventual decay product. The unit has been used to monitor the air in an area undergoing preparations for cleanup operations and operated successfully in a continuous mode for well over a year.

\section{SUMMARY}

A method is described for continuous and simultaneous measurement of ${ }^{220} \mathrm{Rn}$ and ${ }^{222} \mathrm{Rn}$ in air using scintillation flasks. The method involves air being pumped through two scintillation flasks, or cells, assembled in a serial flow pattern and uses difference of half lives to determine the concentration of each radon isotope in the sampled air volume. A unit was assembled and tested to determine the ability for separating signals in the simultaneous presence of the two radon isotopes and was used at a facility where ${ }^{220} \mathrm{Rn}$ presented a worker exposure issue. Using the method presented, systems can be easily built using off-the-shelf components that are expected to provide stable and sensitive measurement results over a wide variety of environmental conditions. Finally, the approach makes use of isotope-independent calibration factors and could easily be

modified for use with a single detector when only one of the radon isotopes is expected to be present.

\section{REFERENCES}

Lucas, H. F. 1957. Improved Low-Level Alpha-Scintillation Counter for Radon, Review of Scientific Instruments 28: 680-683. 
Table 1. Coefficients for relating the decays of radon progeny during a count interval.

\begin{tabular}{|l|c|c|c|c|c|c|}
\hline $\begin{array}{c}\text { Measurement } \\
\text { Interval } \\
\text { (min) }\end{array}$ & $\mathbf{k}_{\mathbf{A}}$ & $\mathbf{k}_{\mathbf{C}}$ & $\mathbf{k}_{\mathbf{D}}$ & $\mathbf{j}_{\mathbf{A}}$ & $\mathbf{j}_{\mathbf{B}_{\mathbf{1}}}$ & $\mathbf{j}_{\mathbf{B}_{\mathbf{2}}}$ \\
\hline 5 & $4.7 \mathrm{e}-01$ & $1.1 \mathrm{e}-03$ & $8.5 \mathrm{e}-05$ & $7.0 \mathrm{e}-01$ & $5.8 \mathrm{e}-02$ & $6.4 \mathrm{e}-02$ \\
\hline 10 & $6.5 \mathrm{e}-01$ & $5.9 \mathrm{e}-03$ & $2.6 \mathrm{e}-04$ & $9.0 \mathrm{e}-01$ & $1.5 \mathrm{e}-01$ & $7.7 \mathrm{e}-02$ \\
\hline 15 & $7.5 \mathrm{e}-01$ & $1.2 \mathrm{e}-02$ & $5.4 \mathrm{e}-04$ & $9.6 \mathrm{e}-01$ & $2.4 \mathrm{e}-01$ & $7.3 \mathrm{e}-02$ \\
\hline 30 & $8.7 \mathrm{e}-01$ & $6.3 \mathrm{e}-02$ & $1.9 \mathrm{e}-03$ & $1.0 \mathrm{e}+00$ & $4.9 \mathrm{e}-01$ & $5.2 \mathrm{e}-02$ \\
\hline 60 & $9.4 \mathrm{e}-01$ & $2.0 \mathrm{e}-01$ & $6.5 \mathrm{e}-03$ & $1.0 \mathrm{e}+00$ & $7.6 \mathrm{e}-01$ & $2.4 \mathrm{e}-02$ \\
\hline 120 & $9.7 \mathrm{e}-01$ & $4.5 \mathrm{e}-01$ & $2.9 \mathrm{e}-03$ & $1.0 \mathrm{e}+00$ & $9.5 \mathrm{e}-01$ & $5.1 \mathrm{e}-03$ \\
\hline 180 & $9.8 \mathrm{e}-01$ & $6.1 \mathrm{e}-01$ & $5.3 \mathrm{e}-02$ & $1.0 \mathrm{e}+00$ & $9.9 \mathrm{e}-01$ & $1.1 \mathrm{e}-03$ \\
\hline 360 & $9.9 \mathrm{e}-01$ & $8.0 \mathrm{e}-01$ & $1.3 \mathrm{e}-01$ & $1.0 \mathrm{e}+00$ & $1.0 \mathrm{e}+00$ & $1.0 \mathrm{e}-05$ \\
\hline 480 & $9.9 \mathrm{e}-01$ & $8.5 \mathrm{e}-01$ & $1.8 \mathrm{e}-01$ & $1.0 \mathrm{e}+00$ & $1.0 \mathrm{e}+00$ & $4.6 \mathrm{e}-07$ \\
\hline & $\mathbf{j}_{\mathbf{C}_{\mathbf{1}}}$ & $\mathbf{j}_{\mathbf{C}_{\mathbf{2}}}$ & $\mathbf{j}_{\mathbf{C}_{\mathbf{3}}}$ & $\mathbf{j}_{\mathbf{T}_{\mathbf{B}}}$ & $\mathbf{j}_{\mathbf{b}_{\mathbf{1}}}$ & $\mathbf{j}_{\mathbf{b}_{\mathbf{2}}}$ \\
\hline 5 & $4.8 \mathrm{e}-03$ & $7.4 \mathrm{e}-03$ & $1.5 \mathrm{e}-01$ & $5.0 \mathrm{e}-03$ & $1.8 \mathrm{e}-04$ & $5.5 \mathrm{e}-02$ \\
\hline 10 & $2.2 \mathrm{e}-02$ & $1.8 \mathrm{e}-02$ & $2.6 \mathrm{e}-01$ & $1.1 \mathrm{e}-02$ & $6.5 \mathrm{e}-04$ & $1.1 \mathrm{e}-01$ \\
\hline 15 & $5.1 \mathrm{e}-02$ & $2.7 \mathrm{e}-02$ & $3.3 \mathrm{e}-01$ & $1.6 \mathrm{e}-02$ & $1.4 \mathrm{e}-03$ & $1.5 \mathrm{e}-01$ \\
\hline 30 & $2.0 \mathrm{e}-01$ & $4.1 \mathrm{e}-02$ & $4.2 \mathrm{e}-01$ & $3.2 \mathrm{e}-02$ & $5.1 \mathrm{e}-03$ & $2.9 \mathrm{e}-01$ \\
\hline 60 & $5.1 \mathrm{e}-01$ & $3.7 \mathrm{e}-02$ & $3.4 \mathrm{e}-01$ & $6.3 \mathrm{e}-02$ & $1.8 \mathrm{e}-02$ & $4.8 \mathrm{e}-01$ \\
\hline 120 & $8.7 \mathrm{e}-01$ & $1.2 \mathrm{e}-02$ & $1.1 \mathrm{e}-01$ & $1.2 \mathrm{e}-01$ & $6.3 \mathrm{e}-02$ & $6.9 \mathrm{e}-01$ \\
\hline 180 & $9.7 \mathrm{e}-01$ & $2.9 \mathrm{e}-03$ & $2.6 \mathrm{e}-02$ & $1.8 \mathrm{e}-01$ & $1.1 \mathrm{e}-01$ & $7.6 \mathrm{e}-01$ \\
\hline 360 & $1.0 \mathrm{e}+00$ & $3.3 \mathrm{e}-05$ & $2.9 \mathrm{e}-04$ & $3.2 \mathrm{e}-01$ & $2.7 \mathrm{e}-01$ & $7.3 \mathrm{e}-01$ \\
\hline 480 & $1.0 \mathrm{e}+00$ & $9.4 \mathrm{e}-07$ & $4.1 \mathrm{e}-06$ & $4.1 \mathrm{e}-01$ & $3.5 \mathrm{e}-01$ & $6.3 \mathrm{e}-01$ \\
\hline
\end{tabular}




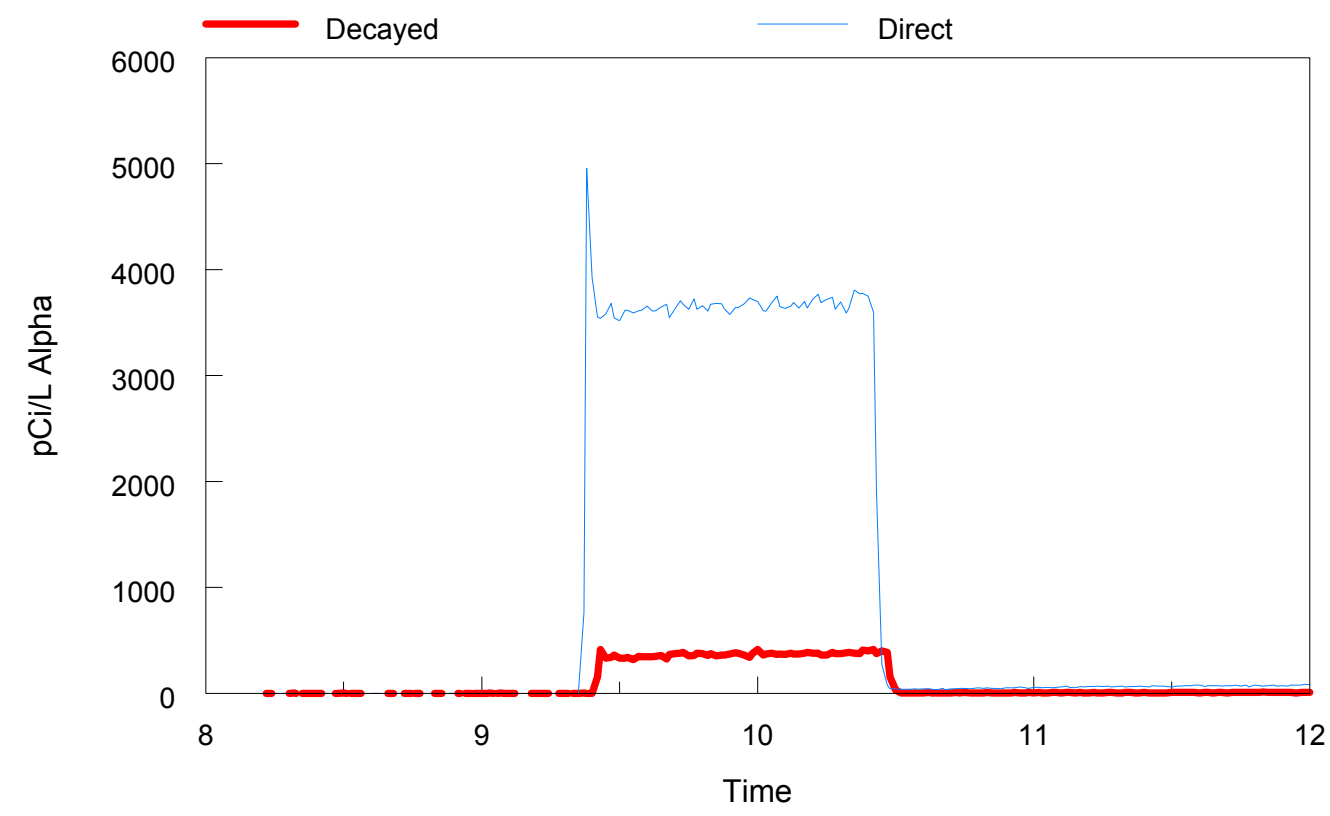

Fig. 2. Results for measurements with a test unit when exposed to only

${ }^{220} \mathrm{Rn}$. This test was performed to determine the decay factor, $\Lambda$, for the experimental system. The direct data represent the total activity observed in the first cell as shown in Fig. 1 while the decayed data are for the second cell. The concentrations have not been determined.

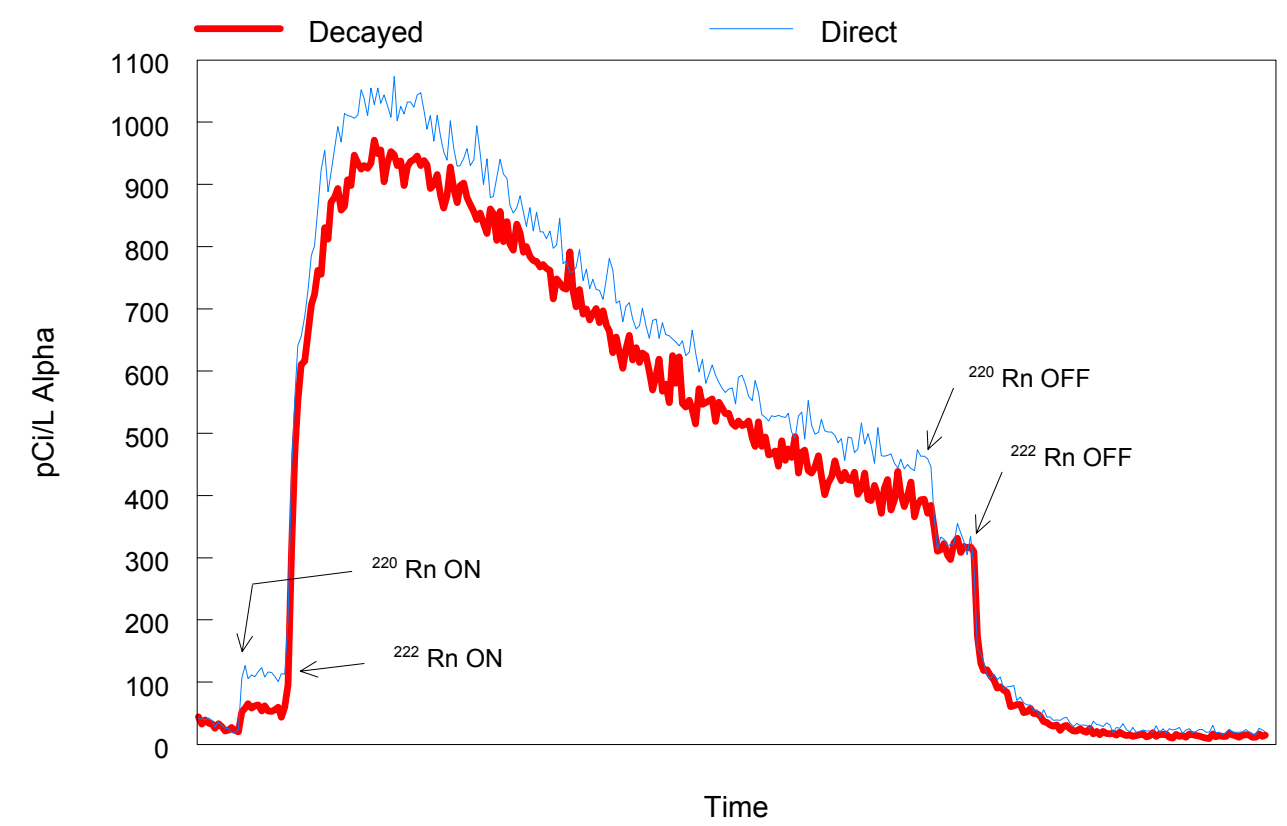

Fig. 3. Results for measurements with a test unit exposed to a high concentration of ${ }^{222} \mathbf{R n}$ and a low concentration of ${ }^{\mathbf{2 2 0}} \mathrm{Rn}$. This test was performed to evaluate the ability of the unit to discriminate ${ }^{220} \mathrm{Rn}$ in the presence of a high concentration of ${ }^{222} \mathrm{Rn}$. The direct data represent the total activity observed in the first cell as shown in Fig. 1 while the decayed data are for the second cell. The concentrations have not been determined. 